\title{
Comunicação
}

[Communication]

\section{Wolbachia spp. interfere na detecção molecular de Ehrlichia canis e Anaplasma platys em cães com microfilaremia}

\author{
[Wolbachia spp. interferes with molecular detection of Ehrlichia canis and Anaplasma \\ platys in microfilaremic dogs] \\ M.S. Xavier ${ }^{1}$, C.N. Fonseca ${ }^{1}$, R.F. Ferreira ${ }^{1}$, T.X. Castro $^{2}$, F.P.G. Neves ${ }^{2}$, \\ A.V. Barbosa ${ }^{2}$, A.M.F. Cerqueira ${ }^{2}$, N.R.P. Almosny ${ }^{1}$ \\ ${ }^{1}$ Faculdade de Veterinária - Universidade Federal Fluminense - Niterói, RJ \\ ${ }^{2}$ Instituto Biomédico - Universidade Federal Fluminense - Niterói, RJ
}

A família Anaplasmataceae é composta por bactérias Gram-negativo, intracelulares obrigatórias, que formam corpúsculos elementares e são transmitidas por carrapatos (Unver et al., 2003). Anaplasma platys e várias espécies de Ehrlichia spp., inclusive E. canis, desenvolvem doença clínica em diferentes espécies de hospedeiros além do cão doméstico. Wolbachia spp., endossimbionte de insetos, aracnídeos, crustáceos e nematódeos, também pertence à família Anaplasmataceae (Unver et al., 2003; Hartelt et al., 2004). Apesar de essa bactéria não ser conhecida por infectar células de vertebrados, pode ser encontrada na corrente sanguínea desses animais quando liberadas de vermes filarídeos que estejam infestando-os (Unver et al., 2003).

A precisão do diagnóstico da erlichiose e da anaplasmatose caninas vem melhorando juntamente com o avanço tecnológico de metodologias, principalmente aquelas relacionadas com biologia molecular. A reação em cadeia da polimerase (PCR) é eficaz na detecção de níveis baixos de parasitemia em tecidos de cães. A PCR e o sequenciamento de DNA são métodos sensíveis para detecção e caracterização de hemoparasitas. No entanto, resultados falsos positivos podem ocorrer em função de amplificação inespecífica, contaminação ou uso de baixas temperaturas de anelamento. Uma reação negativa na PCR indica que o DNA alvo não foi detectado, mas não prova que esteja ausente (Little, 2010).
Diversos protocolos existem para detecção de $E$. canis e são baseados em diferentes alvos do seu genoma, como 16S RNAr, gene que determina a síntese de RNA ribossomal (Mavromatis et al., 2006; Little, 2010), p28, multigene de síntese de proteínas de superfície, $d s b$ ("disulfide bond formation protein"), que determina síntese de proteínas com ligações dissulfeto, p30 ("major outer membrane multigene"), multigene de síntese de membrana externa, virB9, que determina síntese da proteína de superfície altamente antigênica (Mavromatis et al., 2006 ), entre outros. No entanto, os alvos 16S RNAr e p30 são os mais comumente usados (Little, 2010).

A pesquisa do DNA através de PCR, usando iniciadores ou "primers" baseados no gene 16S RNAr, permite a detecção de várias espécies da família Anaplasmataceae, inclusive do gênero Wolbachia, e têm sido usados em pesquisas em diferentes materiais biológicos, como invertebrados, sangue e outros tecidos de animais e humanos (Inokuma et al., 2000; Hartelt et al., 2004, Martin et al., 2005). Wolbachia spp. pode interferir na PCR de amostras de sangue de cães para detecção de hemoparasitas da familia Anaplasmataceae (Hartelt et al., 2004). O presente relato descreve essa interferência em testes para pesquisa de Ehrlichia canis e Anaplasma platys em sangue de cães da região litorânea do Rio de Janeiro.

Recebido em 21 de julho de 2014

Aceito em 7 de abril de 2015

E-mail: marciasouzaxavier@gmail.com 
Durante a campanha de vacinação antirrábica, em setembro de 2007, foram coletadas, por venopunção cefálica ou jugular, amostras de sangue em 155 cães, no município de Maricá, Região dos Lagos, no litoral do Estado do Rio de Janeiro/BR. A seleção dos animais foi feita por conveniência, de acordo com o consentimento do proprietário em permitir que seu cão participasse do estudo, assinando termo de consentimento, e o trabalho aprovado pelo Comitê de Ética em Pesquisa Animal (CEPA), da Universidade Federal Fluminense, sob o número 164/09.

As amostras sanguíneas com anticoagulante (EDTA) foram usadas para extração de DNA utilizando-se o kit comercial da GE "Genomic Blood Purifcation Kit" (Amersham Biosciences, Piscataway, EUA), de acordo com as instruções do fabricante, para posterior teste de PCR. Foram feitos esfregaços sanguíneos e corados por método de Romanowisky (corante May Grunwald-Giemsa), usados para pesquisa direta de hemoparasitas em microscopia óptica (Nikon, Tóquio, Japão) com objetivas de 40X e 100X.

Foram utilizados dois protocolos de PCR para a detecção de membros da família Anaplasmataceae. Todas as amostras positivas foram submetidas a reações para pesquisar as espécies E. canis e A. platys. A Tabela 1 apresenta os alvos, os iniciadores empregados, o tamanho esperado dos amplicons e as referências. Cinco amostras que foram positivas nas reações para Anaplasmataceae, mas negativas nas reações de detecção das espécies investigadas, foram selecionadas por causa de suas bandas fortes e evidentes na revelação em gel, para serem submetidas a novas amplificações para sequenciamento do DNA. Os amplicons obtidos foram purificados através do kit "PureLink ${ }^{\mathrm{TM}}$ Nucleic Acid Purification Kit" (Invitrogen, São Paulo, Brasil). A quantificação do DNA purificado foi feita com eletroforese em gel de agarose, por comparação com bandas do "Low Mass DNA Ladder" (Invitrogen, São Paulo, Brasil), utilizando-se, para o sequenciamento, uma quantidade mínima aproximada de 40ng. O sequenciamento utilizou o protocolo Big Dye Terminator Cycle Sequencing Kit Version 1.1, seguindo as especificações do fabricante, no sequenciador 3130/3130X/Genetic Analyzer Applied Biosystems (Hitachi USA 850 Lincoln Drive Foster City CA94404USA). Ambas as fitas de cada amplicon foram sequenciadas, sendo alinhadas e editadas através do Bio Edit sequence alignment editor v.7.1.11 (http://mbio.ncsu.edu/BioEdit/bioedit.html). As sequências obtidas foram submetidas $\mathrm{e}$ comparadas com aquelas disponíveis no GenBank (www.ncbi.nlm.nih.gov/genbank), utilizando-se o programa Blast (http://www.ncbi. nlm.nih.gov/blast).

Tabela 1. Iniciadores utilizados para a detecção de hemoparasitas em amostras sanguíneas de cães da região litorânea do Rio de Janeiro/BR, setembro de 2007

\begin{tabular}{|c|c|c|c|}
\hline Alvo & Iniciadores /Sequência $\left(5^{\prime} \rightarrow 3^{\prime}\right)$ & $\begin{array}{l}\text { Amplicon } \\
\text { (pb) }\end{array}$ & Referência \\
\hline Anaplasmataceae & $\begin{array}{l}1 \text { - ECC - AGA ACG AAC GCT GGC GGC AAG C } \\
\text { ECB - CGT ATT ACC GCG GCT GCT GGC A }\end{array}$ & 478 & $\begin{array}{l}\text { Dawson } e t \\
\text { al., } 1996\end{array}$ \\
\hline Anaplasmataceae & $\begin{array}{l}2 \text { - EHR16SR/ GGT ACC YAC AGA AGA AGT CC } \\
\text { EHR16SD TAG CAC TCA TCG TTT ACA GC }\end{array}$ & 345 & $\begin{array}{c}\text { Inokuma et } \\
\text { al., } 2000\end{array}$ \\
\hline E. canis & $\begin{array}{l}3 \text { - ECAN5 - } \\
\text { CAATTATTTATAGCCTCTGGCTATAGGA } \\
\text { HE3 -TATAGGTACCGTCATTATCTTCCCTAT }\end{array}$ & 389 & $\begin{array}{l}\text { Dawson } e t \\
\text { al., } 1996\end{array}$ \\
\hline A. platys & $\begin{array}{l}4 \text { - PLATYS - GAT TTT TGT CGT AGC TTG CTA } \\
\text { TG } \\
\text { EHR16SD - TAG CAC TCA TCG TTT ACA GC }\end{array}$ & 678 & $\begin{array}{l}\text { Martin et } \\
\text { al., } 2005\end{array}$ \\
\hline A. platys & $\begin{array}{l}5 \text { - Gro Aplatys 35s - AGC GTA GTC CGA TTC TCC } \\
\text { AGT TTT } \\
\text { Gro Aplatys 550as - TCG CCG TTA GCA GAG ATG } \\
\text { GTAG }\end{array}$ & 469 & $\begin{array}{l}\text { Beall et al., } \\
\quad 2008\end{array}$ \\
\hline
\end{tabular}


Um total de 62 amostras (40\%) foi positivo para Anaplasmataceae nos testes de PCR, sendo que 51 dessas não foram positivas para $E$. canis e/ou A. platys. Dessas, as cinco amostras selecionadas para sequenciamento por causa de suas bandas fortes e evidentes na revelação em gel mostraram, quando comparadas às sequências do Gen Bank, similaridade entre $88 \%$ a $100 \%$ com Wolbachia spp., também da família Anaplasmataceae. Esses cinco cães eram microfilarêmicos. A detecção de Wolbachia spp. em PCR para Anaplasmataceae em cães já foi relatada (Unver et al., 2003), sendo que não houve evidência de microfilaremia, e os autores discutiram a possibilidade de que essa bactéria estivesse associada a quadro fisiopatogênico. No caso do presente estudo, as amostras eram de cães microfilarêmicos e, provavelmente, havia uma concentração elevada do DNA de Wolbachia spp., o que explica a presença de fortes bandas na revelação em gel e dificultaria a detecção de outras espécies da mesma família taxonômica.

O sequenciamento foi feito a partir do produto amplificado dos iniciadores para amplificar DNA de todos os membros de Anaplasmataceae (Inokuma et al., 2000); portanto, não se pode descartar a possibilidade da presença de DNA de mais do que uma espécie dessa família. Estudos mostraram que, mesmo quando existiam mais de uma bactéria Anaplasmataceae na amostra clínica, a concentração de DNA que predominava poderia interferir na positividade quando utilizados iniciadores baseados no gene 16S rRNA (Hancock et al., 2001; Suksawat et al., 2001, com correção dos autores em 2002; Hartelt et al., 2004). Assim, embora não tenham sido testadas outras espécies além de E. canis e $A$. platys, as amostras deste estudo que foram negativas para $E$. canis e/ou A. platys, também podem ter tido interferência da concentração do
DNA de Wolbachia spp. nos cães microfilarêmicos.

Segundo Little (2010), como em qualquer método de diagnóstico, também é necessária validação externa, e a sensibilidade nem sempre é a mesma observada em controles clonados em plasmídeos quando comparados a amostras clínicas, como as do presente estudo, ressaltando a importância do sequencimento nesses casos. Inokuma et al. (2003) também afirmaram que o sequenciamento parcial do gene $16 \mathrm{~S}$ rRNA pode não permitir a identificação do agente até o nível de espécie, mas que a comparação com registros no GenBank identifica espécies correlacionadas, o que pode ser considerado suficiente para identificação de amostras clínicas e para orientar o tratamento adequado.

Um estudo realizado para detecção do DNA de Wolbachia em amostras sanguíneas de cães microfilarêmicos conseguiu uma sensibilidade de detecção do DNA para uma concentração mínima de 150 microfilárias/ $\mu \mathrm{L}$ de sangue (Rossi et al., 2010). Os animais do nosso estudo tinham microfilárias no esfregaço sanguíneo possuindo em torno de 333 microfilárias $\mu \mathrm{L}$ de sangue, mais do que o dobro observado por aqueles autores, podendo ter elevada concentração desse DNA e interferindo na amplificação do DNA de Ehrlichia canis e/ou A. platys. Foi concluído, portanto, que, em animais microfilarêmicos, a reação de PCR para pesquisa de $E$. canis e/ou A. platys pode sofrer interferência e deve ser realizada com complementação de sequenciamento e por reações que utilizem iniciadores baseados em regiões específicas do genoma de cada uma das espécies.

Palavras-chave: cão, Erlichiose, sequenciamento, microfilarêmico, PCR

\section{ABSTRACT}

This report aimed to study the interference in molecular testing for Ehrlichia canis and Anaplasma platys in blood of 155 dogs from the coastal region of Rio de Janeiro. Five Anaplasmataceae positive samples but negative for E. canis and A. platys, from microfilaremic animals, were chosen for sequencing. These sequences, when compared to Gen et Bank database, showed $88 \%$ to $100 \%$ similarity with Wolbachia spp. denoting an interference in the detection of DNA from other members of Anaplasmataceae, possibly due to a high concentration of Wolbachia spp. DNA.

Keywords: dogs, PCR, ehrlichiosis, sequencing, microfilaremic 


\section{AGRADECIMENTOS}

Aos médicos veterinários Msc. Alexandre Garcia de Sá e Dra. Renata Fernandes Ferreira pela doação de controles positivos de E. Canis e A. platys, à Fundação de Apoio à Pesquisa Carlos Chagas Filho (FAPERJ) e ao Conselho Nacional de Desenvolvimento Científico e Tecnológico (CNPq).

\section{REFERÊNCIAS}

BEALL, M. J.; CHANDRASHEKAR, R.; EBERTS, M. D. et al. Serological and molecular prevalence of Borrelia burgdorferi, Anaplasma phagocytophilum, and Ehrlichia species in dogs from Minnesota. Vector Borne Zoonotic Dis, v.8, p.455-464, 2008.

DAWSON, J.E.; BIGGIE, K.L.; WANER, C.K. et al. Polymerase chain reaction evidence of Ehrlichia chaffeensis, an etiologic agent of human ehrlichiosis, in dogs from southeast Virginia. Am. J. Vet. Res., v.57, p.1175-1179, 1996.

HANCOCK, S.I.; BREITSCHWERDT, E.B.; PITULLE, C. Differentiation of Ehrlichia platys and $E$. equi infections in dogs by using $16 \mathrm{~S}$ ribosomal DNA-Based PCR. J. Clin. Microbiol., v.39, p.4577-4578, 2001.

HARTELT, K.; OEHME, R.; FRANK, H. et al. Pathogens and symbionts in ticks: prevalence of Anaplasma phagocytophilum (Ehrlichia sp.), Wolbachia sp., Rickettsia sp., and Babesia sp. in southern Germany. Int. J. Med. Microbiol. v.293, suppl.37, p.86-92, 2004.

INOKUMA, H.; BEPPU, T.; OKUDA, M. et al. Epidemiological survey of Anaplasma platys and Ehrlichia canis using ticks collected from dogs in Japan. Vet. Parasitol., v.115, p.343-348, 2003.
INOKUMA, H.; RAOULT, D.; BROUQUI, P. Detection of Ehrlichia platys DNA in brown dog ticks (Rhipicephalus sanguineus) in Okinawa island, Japan. J. Clin. Microbiol., v.38, p.42194221, 2000.

LITTLE, S.E. Ehrlichiosis and anaplasmosis in dogs and cats. Vet. Clin. Small Anim., v.40, p.1121-1140, 2010.

MARTIN, A.R.; BROWN, G.K.; DUNSTAN, R.H. et al. Anaplasma platys: an improved PCR for its detection in dogs. Exp. Parasitol., v.109, p.176-180, 2005.

MAVROMATIS, K.; DOYLE, C.K.; LYKIDIS, A. et al. The genome of the obligately intracellular bacterium Ehrlichia canis reveals themes of complex membrane structure and immune evasion strategies. J. Bacteriol., v.188, p.4015-4023, 2006.

ROSSI, M.I.D.; AGUIAR-ALVES, F.; SANTOS, S. et al. Detection of Wolbachia DNA in blood from dogs infected with Dirofilaria immitis. Exp. Parasitol., v.126, p.270-272, 2010.

SUKSAWAT, J.; PITULlE, C.; ARRAGAALVARADO, C. et al. Coinfection with three Ehrlichia species in dogs from Thailand and Venezuela with emphasis on consideration of 16S ribosomal DNA secondary structure. J. Clin. Microbiol., v.39, p.90-93, 2001; J. Clin. Microbiol., v.40, p.3887, 2002.

UNVER, A.; RIKIHISA, Y.; KAWAHARA, M. et al. Analysis of 16S rRNA gene sequences of Ehrlichia canis, Anaplasma platys, and Wolbachia species from canine blood in Japan. Ann. N. Y. Acad. Sci. v.990, p.692-698, 2003. 